عملكرد و اجزاى عملكرد كندم ديم تحت تأثير شيب زمين و مقادير مصرف بقاياى گياهى

\author{
علىرضا واعظى "، سميرا رضايى يور و محمد بابااكبرى'
}

(تاريخ دريافت: 0/1/

جكيده

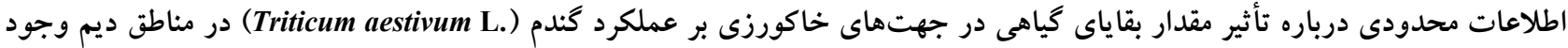

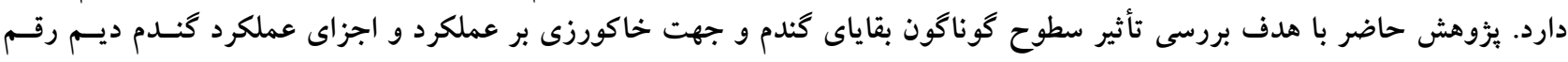
سردارى در سال زراعى ده

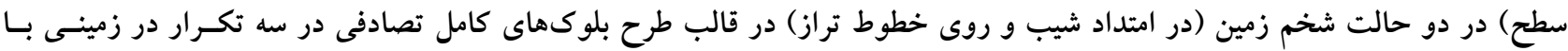

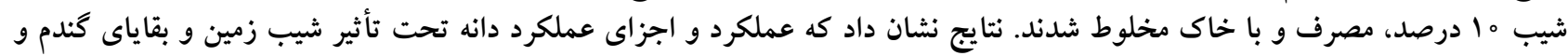

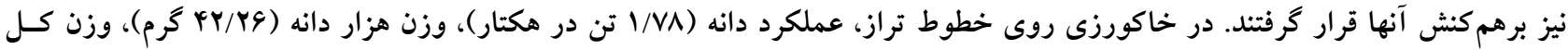

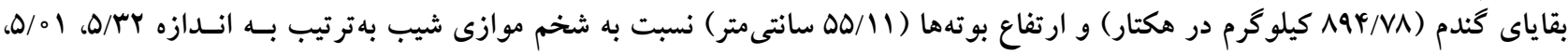

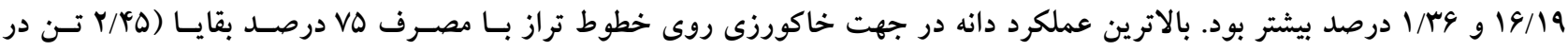

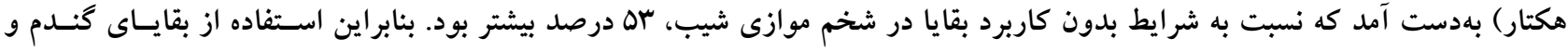

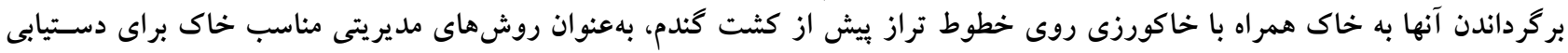

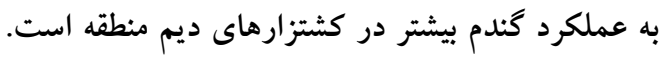

وازههاى كليدى: حفظ آب، خاكورزى روى خطوط تراز، فراهمى آب، بقاياى گندم، منطقه نيمهخشى

ا. كَروه علوم خاك، دانشكده كشاورزى، دانشگاه زنجان، زنجان

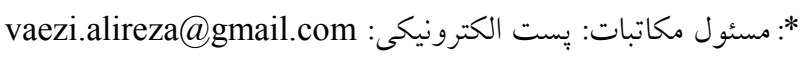


از طريق كاهش دماى خاك و كاهش تبخير از سطح خاك باعث

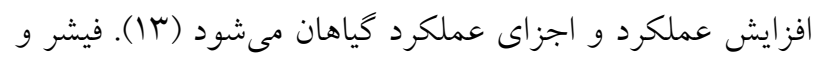

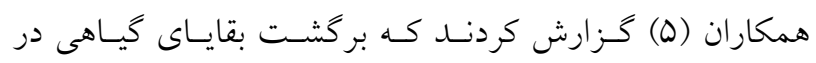

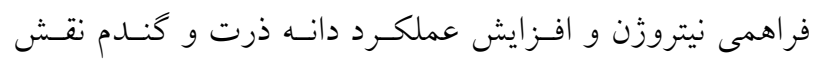

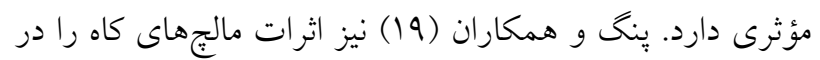

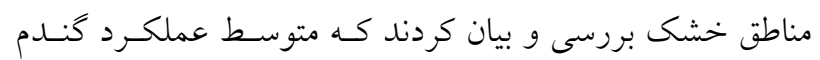

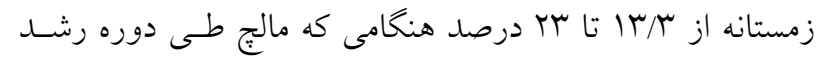
اعمال شد، افزايش يافت. در مطالعهاى ياسين و همكـاران (r9)

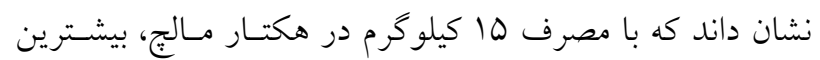

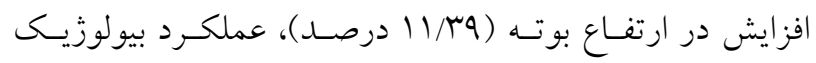

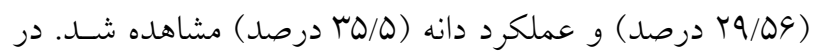
اين مقدار از مالج، سرعت نفوذ و هدايت هيدروليكى بـهـترتيـب

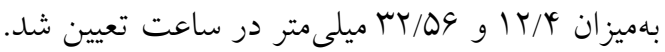

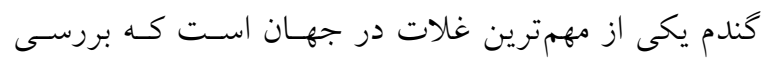

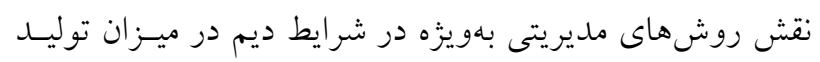

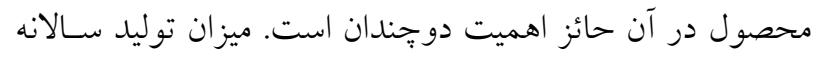

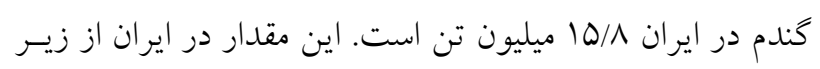

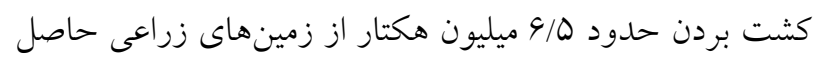

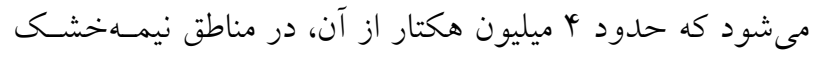

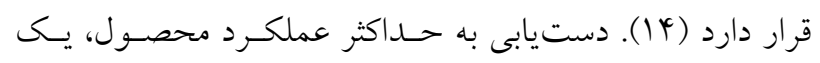

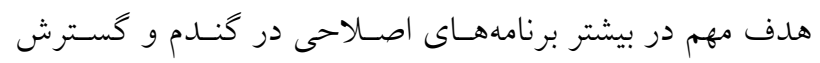

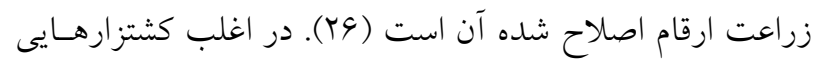

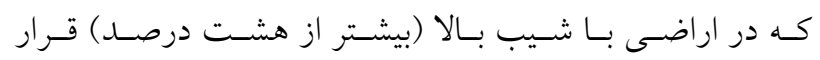

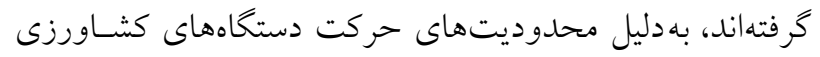

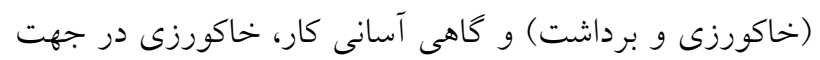

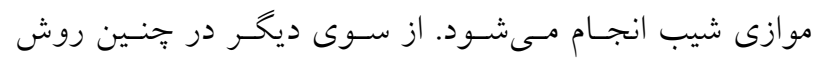

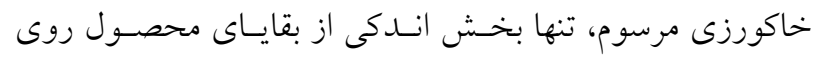

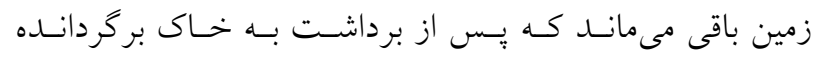

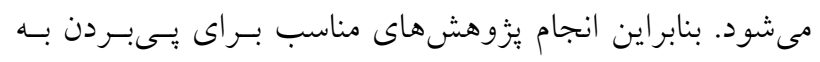

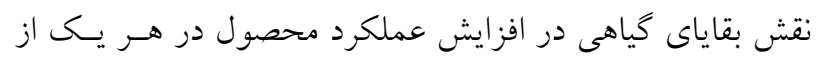

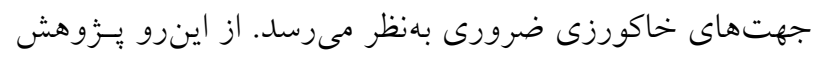

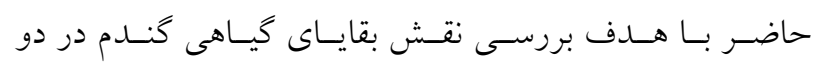

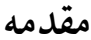

خاكورزى كه عبارت از عمليات بـه هــم زدن مكـانيكى خـاك

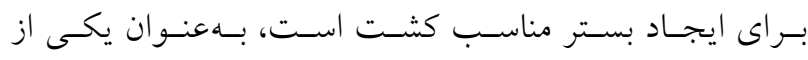

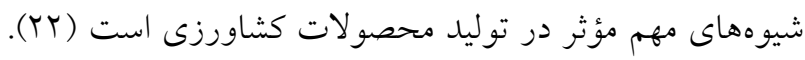

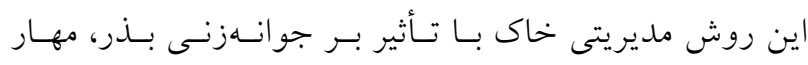

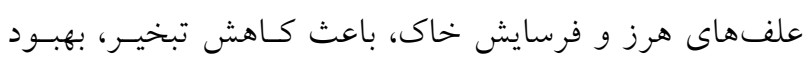

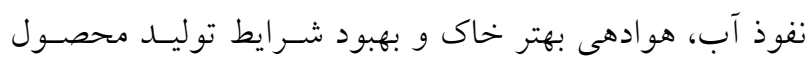

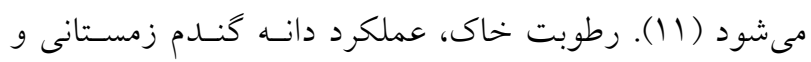

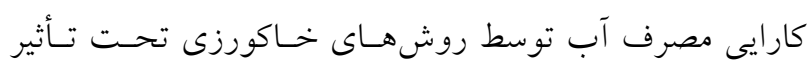

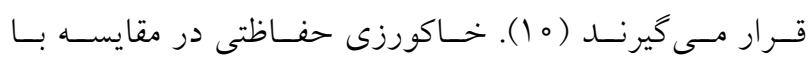

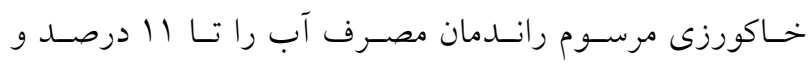

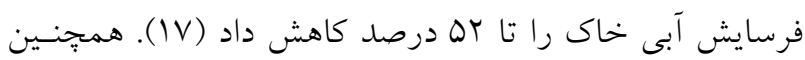

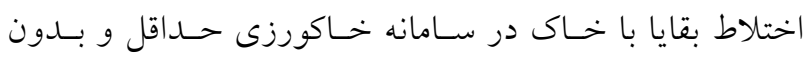

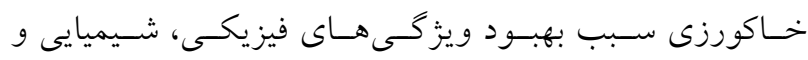

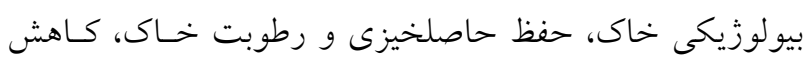

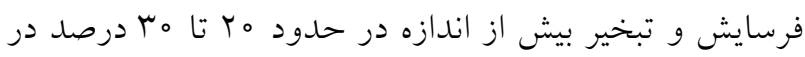

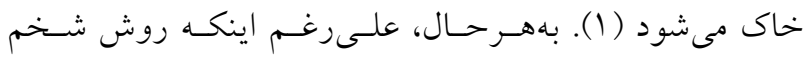

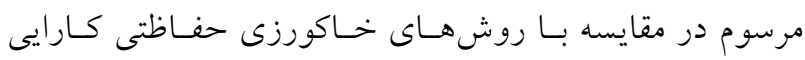

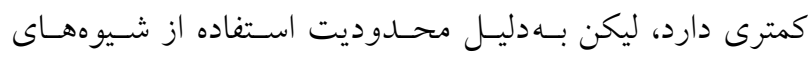

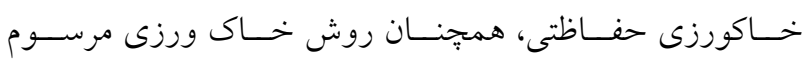

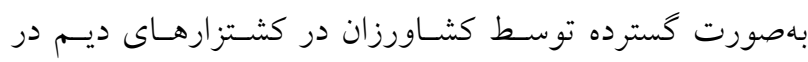

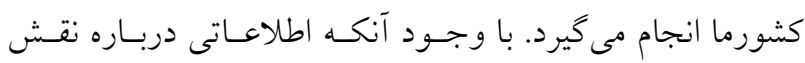

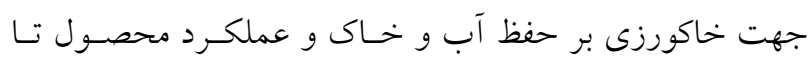

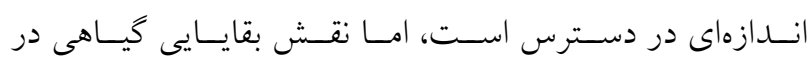
جهت هاى كوناكون خاكورزى، موضوعى نيازمند بررسى است.

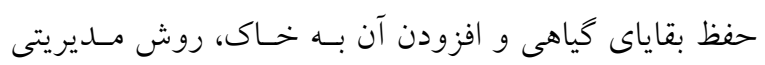

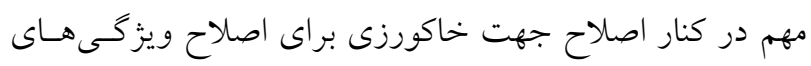
خاك، حفظ آب و كاهش فرسايش خاك است. بقايـاى كياهى

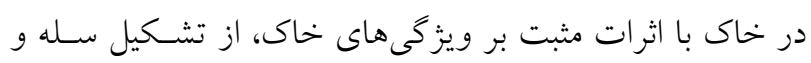

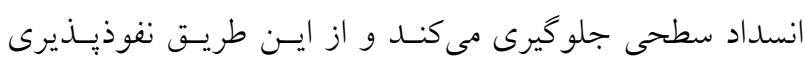

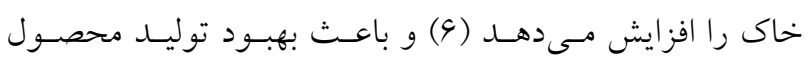
مىشود (Tr). حفظ بقاياى كَاهى در كنار حفظ رطوبت خـاك، 


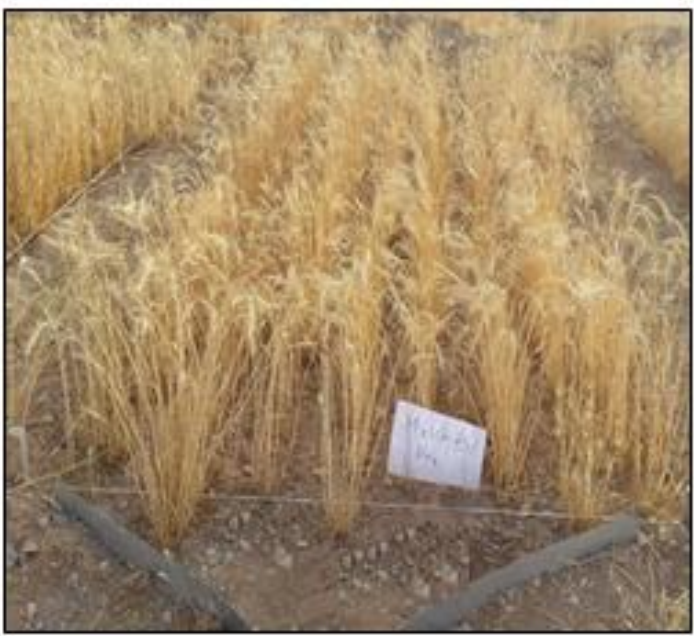

(ب)

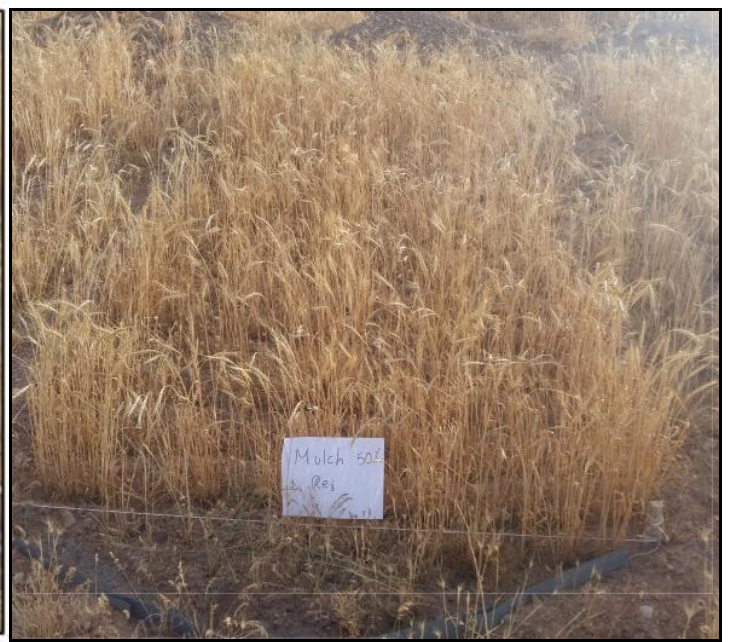

(الف)

شكل ا. كرت آزمايشى زير كشت گندم ديم در الف) جهت موازى شيب و ب) روى خطوط تراز

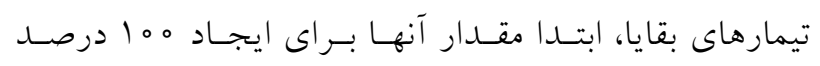

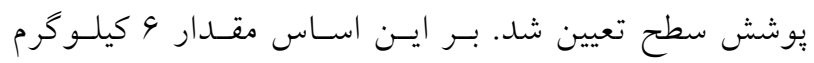

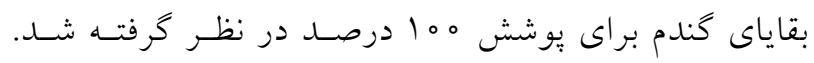

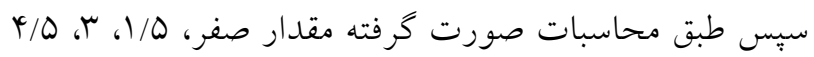

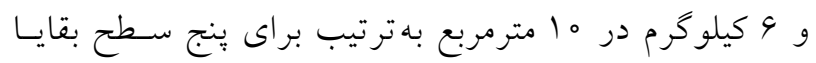

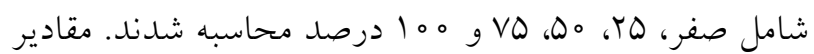

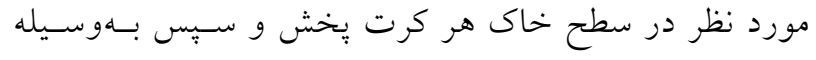

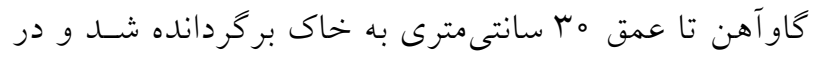

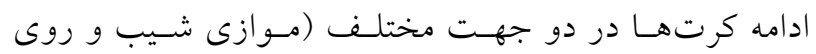

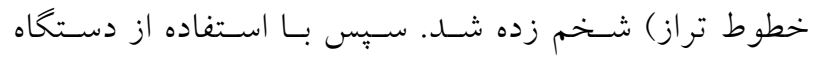
خطى كار 9 رديفى (با عمق كشت جهار تا شش سـانتى متسر) كه وسيله رايج در كشور است، كندم رقم سردارى در اوائسل

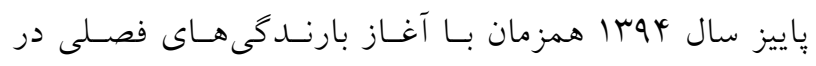

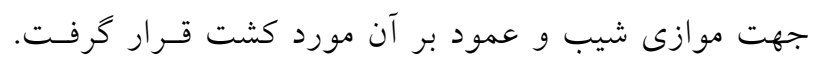

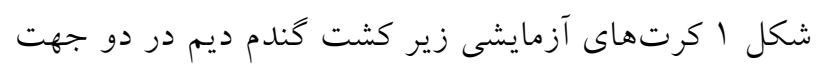
خاكورزى را نشان مى دهد.

تعيين ويزگى هاى خاى

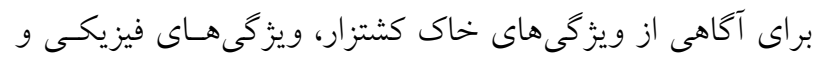

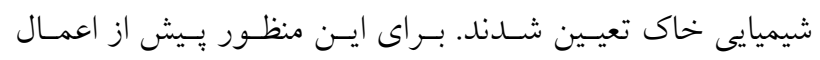

جهت خاكورزى از نظر بهبود عملكرد گُندم ديـم در كشـزارى ديم در منطقه نيمهخشى انجام گرفت.

\section{مواد و روشها}

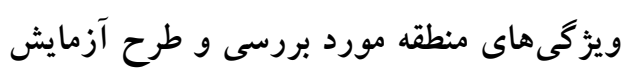

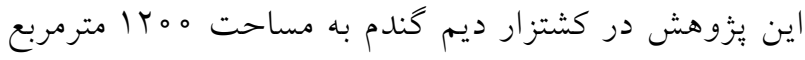

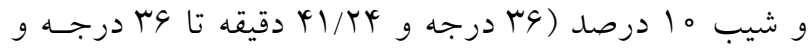
وق

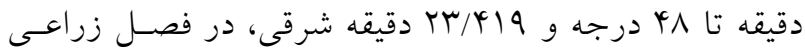
40

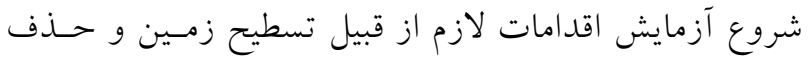

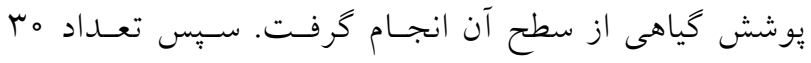

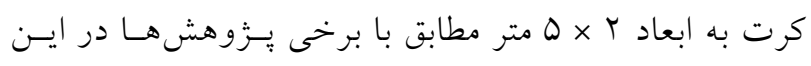

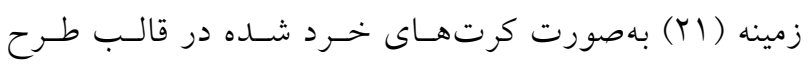

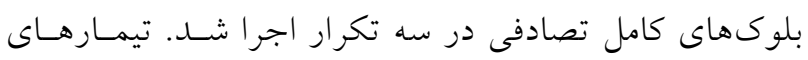

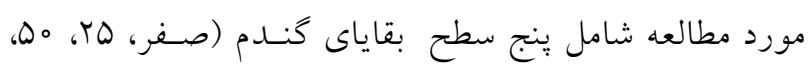
V و م 100

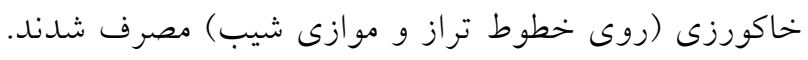

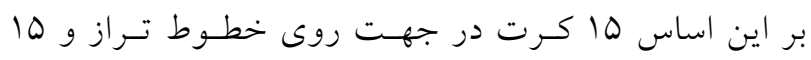
كرت در جهت موازى شيب طراحى شـــ. بـهمنظـور اعمـال 
جدول ا. برخى ويزّىهاى فيزيكى و شيميايى خاك مورد مطالعه

\begin{tabular}{|c|c|}
\hline ميانگين & ويزگى \\
\hline $40 / 4 \mathrm{~V}$ & 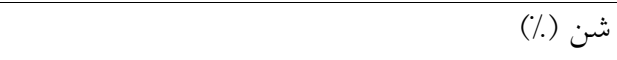 \\
\hline $10 \%$ & 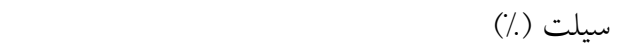 \\
\hline$r q / 49$ & 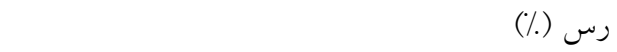 \\
\hline$M / / 4$ & سنخر يزه (./) \\
\hline $1 / 14$ & جرم مخصوص ظاهرى (g/cm) \\
\hline$\circ / 11$ & ميانحين وزنى قطر خاكدانههاى بايدار در آب (mm) \\
\hline$V / \varphi_{0}$ & 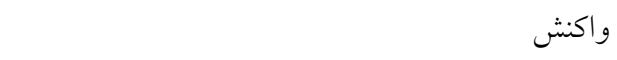 \\
\hline $11 / N T$ & ظرفيت تبادل كاتيونى (meq/log) \\
\hline$r / Q V$ & هدايت الكتريكى (dS/m) \\
\hline$\circ / 4 V$ & ماده آلى (\%) \\
\hline $11 / r r$ & كربنات كلسيم معادل (٪) \\
\hline $0 / 94$ & درصد سديم تبادلى \\
\hline
\end{tabular}

(Yq/49 درصد)، خاك كشتزار داراى بافت لومرسشنى است. با

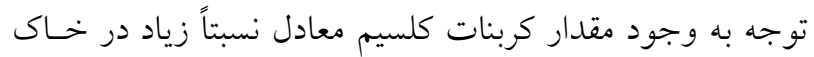

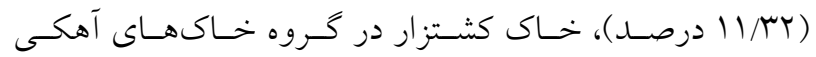

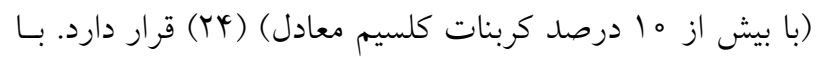

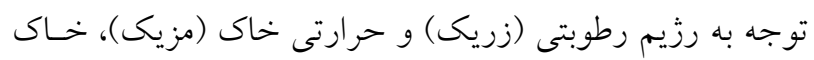
مورد بررسى بـر اسـاس روش ردهبنـدى آمريكـايى در دو رده

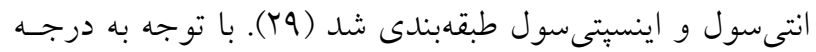
شورى (Y/OV) دسىزينس بر متر) و و واكـنش (V/4) و نيـز :ـايين

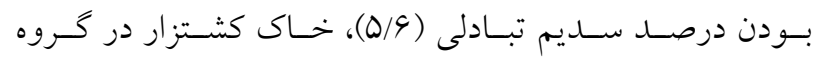
خاكهاى غير شور و غير قليا (Y) قرار دارد. خاك داراى مقــار

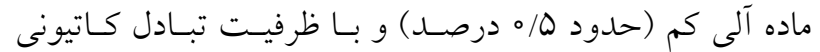

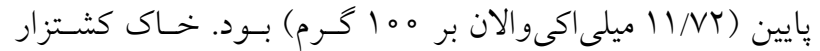

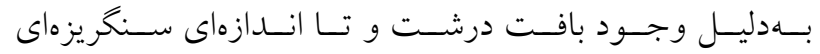

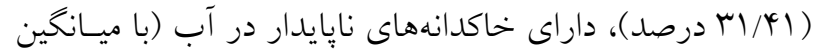
وزنى قطر /(/ه ميلىمتـر) اسـت و در عسين حسال نفوذيـذيرى خاك بالا (N/N اسانتى متر بر ساعت) است.

\section{تعيين عملكرد و اجزاى عملكرد گندم}

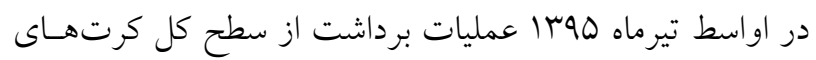

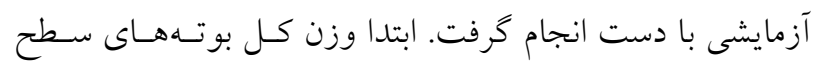

تيمارها، نمونهـــردارى خـاك بـهـهـورت تصـادفى بـــاى تعيـين

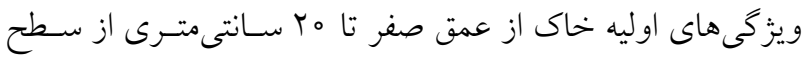

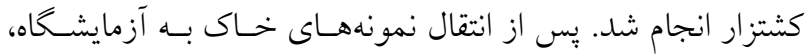

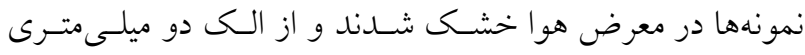

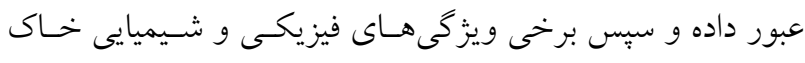

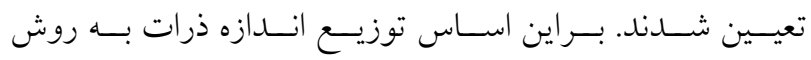

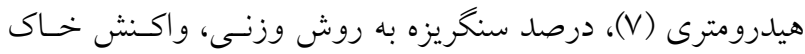

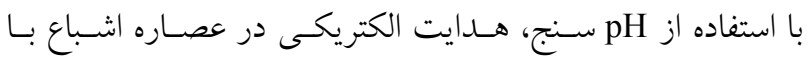

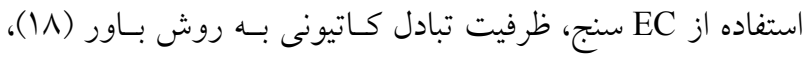

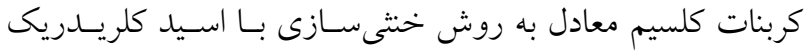

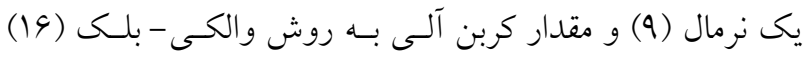

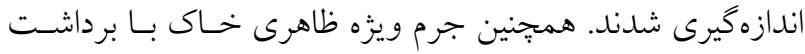

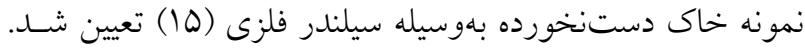

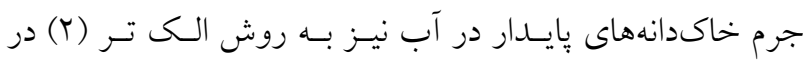

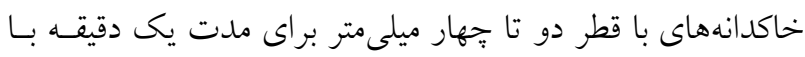

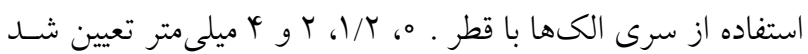

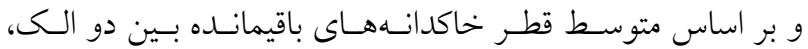
ميانخين وزنى قطر خاكدانهها بهدست آمد. جدول انتايج برخى ويزگى هاى فيزيكى و شسيميايى خـاك

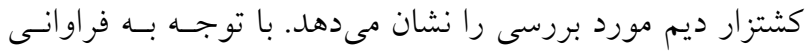

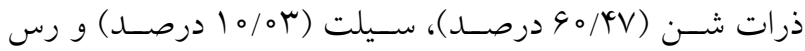


كُندم در كشتزار ديم مورد بررسى، پايين بودن بارورى خاك

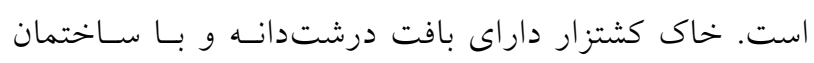

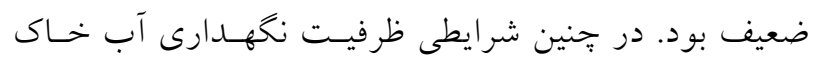

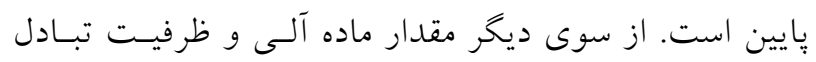

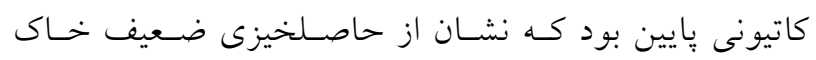

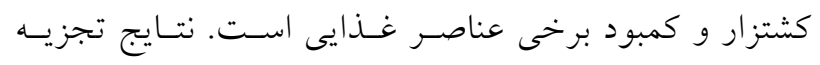

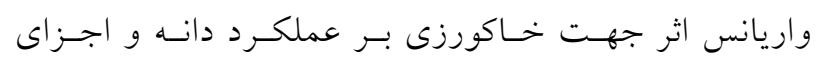

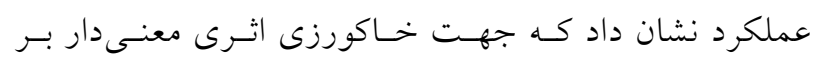

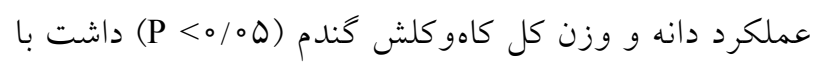

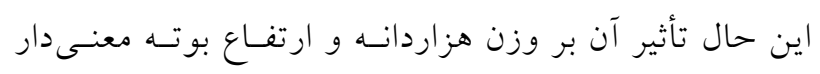

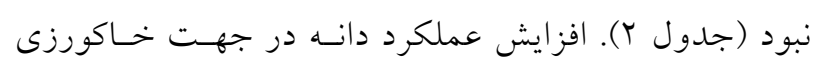

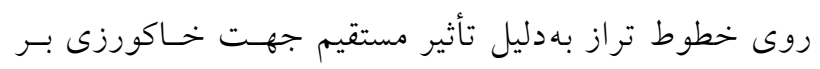

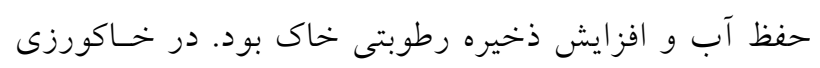
روى خطوط تراز بهدليل افزايش مقدار آب در دسترس، كياه

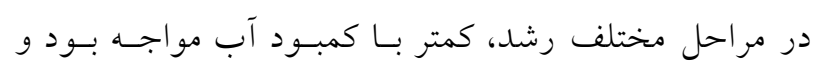

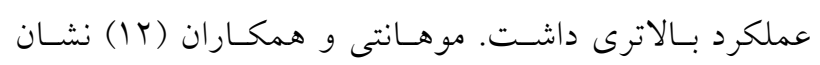

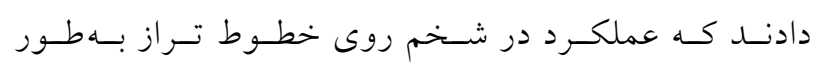

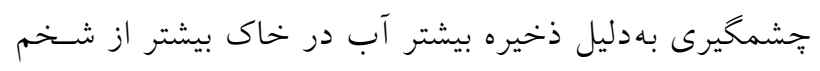

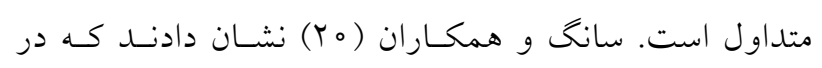

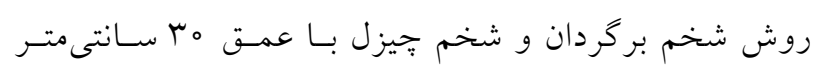

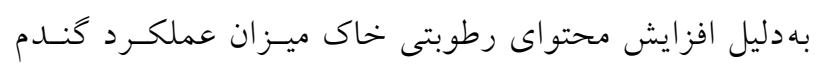

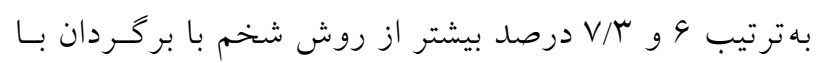

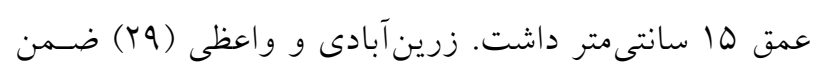

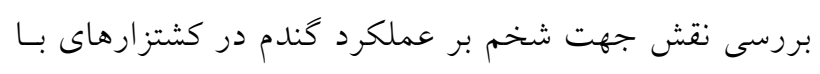

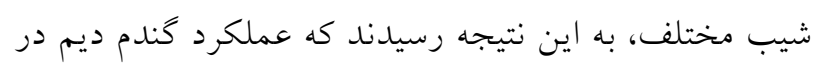

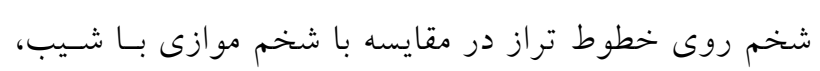

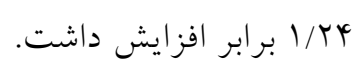

تأثير مقدار مصرف مالج كاهو كلـش بــر عملكـــد و اجـزاى عملكرد گندم

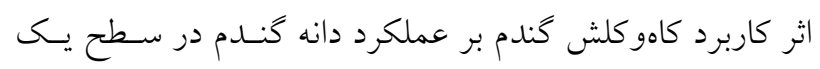

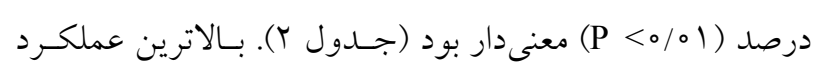

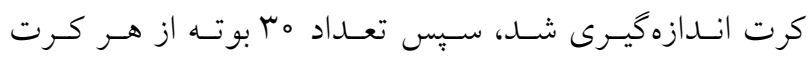

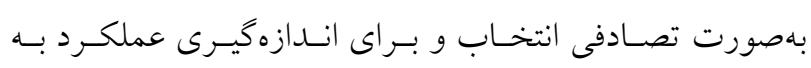

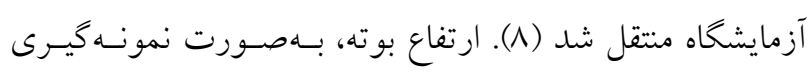

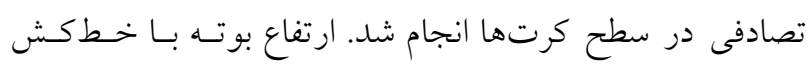
بزرى فلزى ازحد فاصل بين يقه در سطح خاك تا انتهاى سـنبله

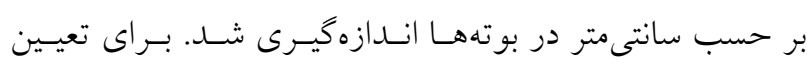

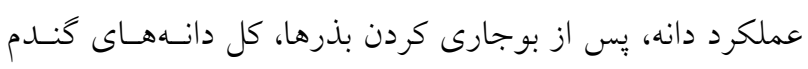

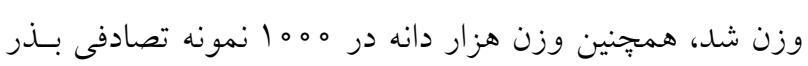

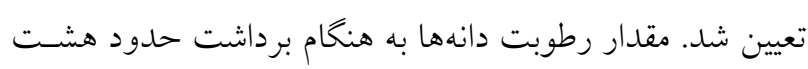
درصد بود.

\section{تجزيه و تحليل دادهها}

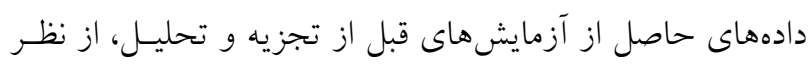

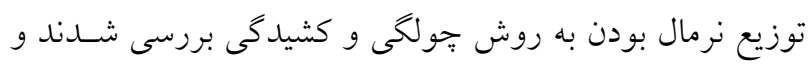

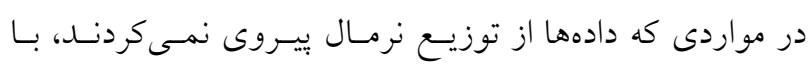

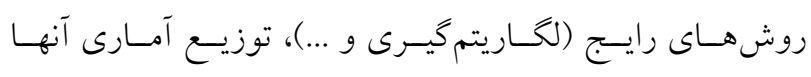

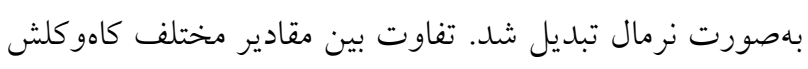

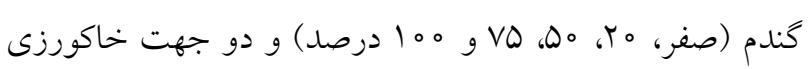

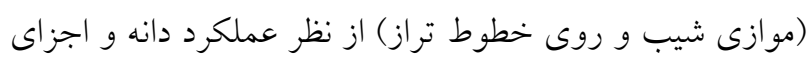

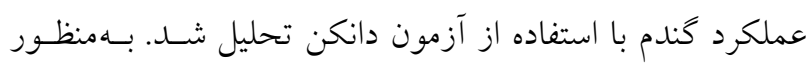

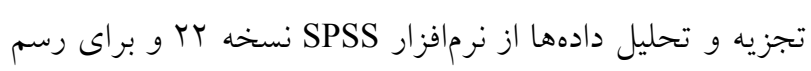

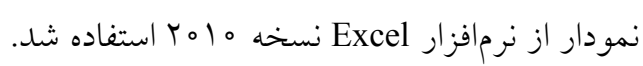

\section{نتايج و بحث}

تأثير جهت خاكورزى بر عملكرد و اجزاى عملكرد گندم

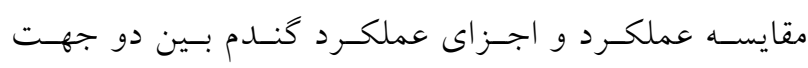

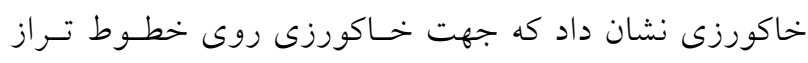

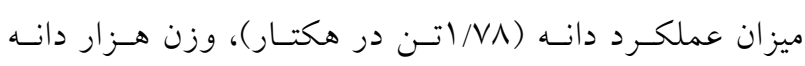

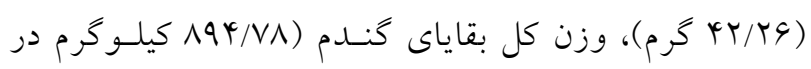

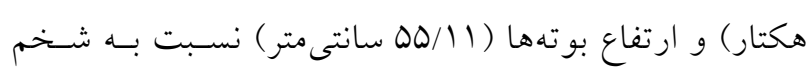

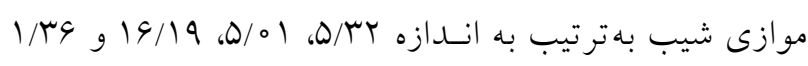

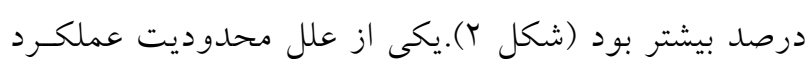



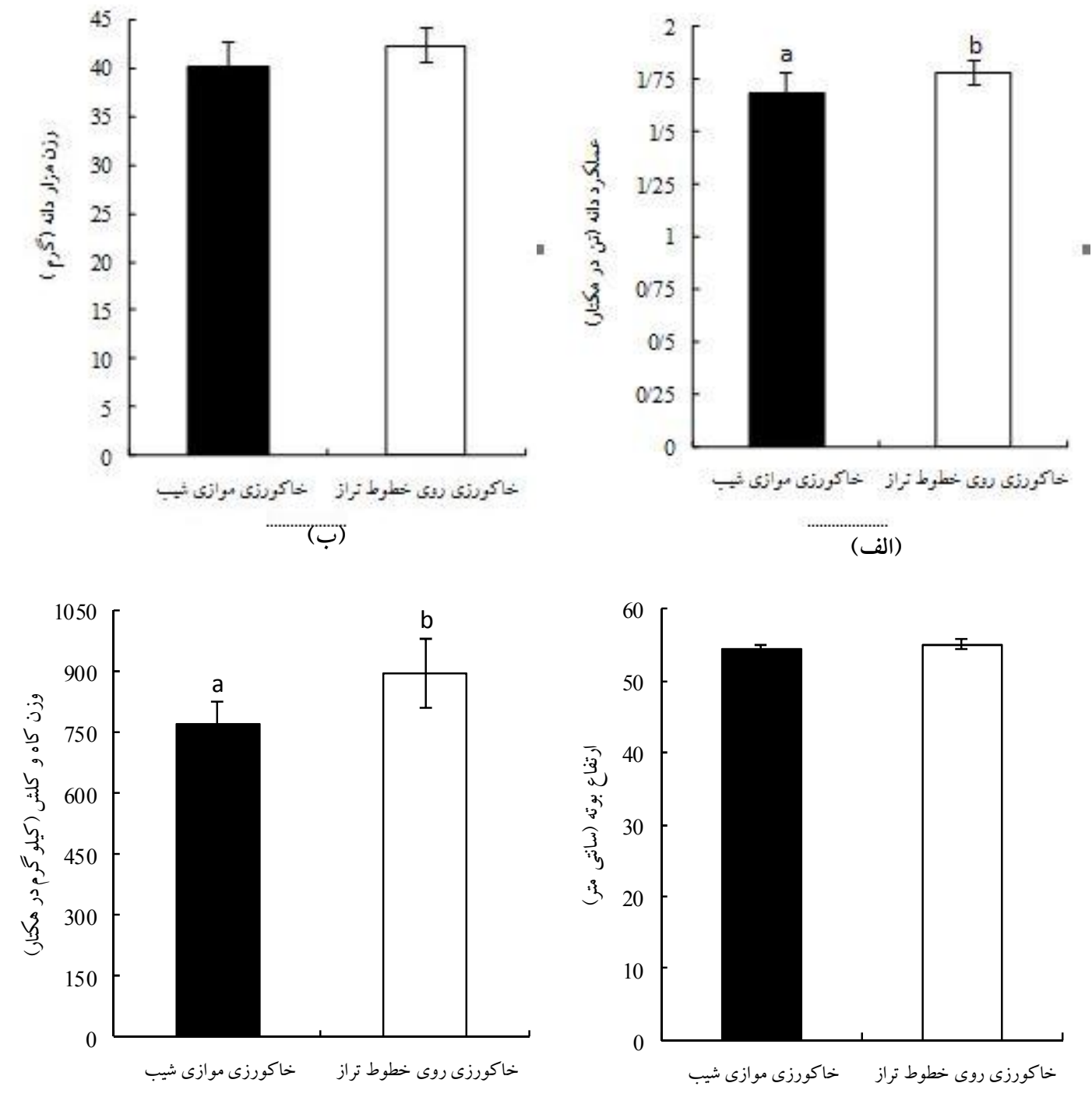

(د)

(ج)

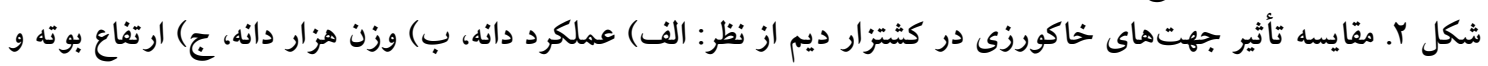

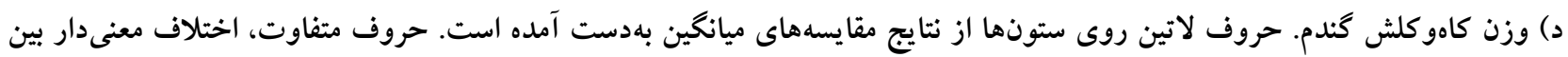
دو جهت خاكورزى را نشان مىدهد.

\begin{tabular}{|c|c|c|c|c|c|}
\hline \multicolumn{4}{|c|}{ ميانگين مربعات } & \multirow[b]{2}{*}{ درجه آزادى } & \multirow[b]{2}{*}{ منبع تغيير } \\
\hline 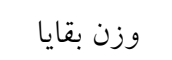 & ارتفاع بوته & وزن هزار دانه & عملكرد دانه & & \\
\hline $119 \wedge \Delta V / V^{*}$ & $\varphi / \circ \varphi^{4} \wedge^{\mathrm{ns}}$ & $\mu_{\circ} / 9 \mu^{n s}$ & $\circ / \circ V Y^{*}$ & 1 & جهت خاكورزى \\
\hline rexs $11 / 9^{* *}$ & $|\boldsymbol{Y} / \boldsymbol{\Psi}| 0^{* *}$ & $M r / r q^{* *}$ & $\circ / 4 a \Upsilon^{* *}$ & r & مقدار مصرف مالج \\
\hline $91 \Lambda \circ \psi / Y \psi^{*}$ & $|9 / T| r^{* *}$ & $9 V / 91^{* *}$ & $\circ / \circ 90^{* *}$ & r & جهت خاكورزى × مقدارمصرف مالج \\
\hline $11119 / 49$ & l/AVG & $|r / F|$ & $0 / 010$ & 19 & خطا \\
\hline
\end{tabular}



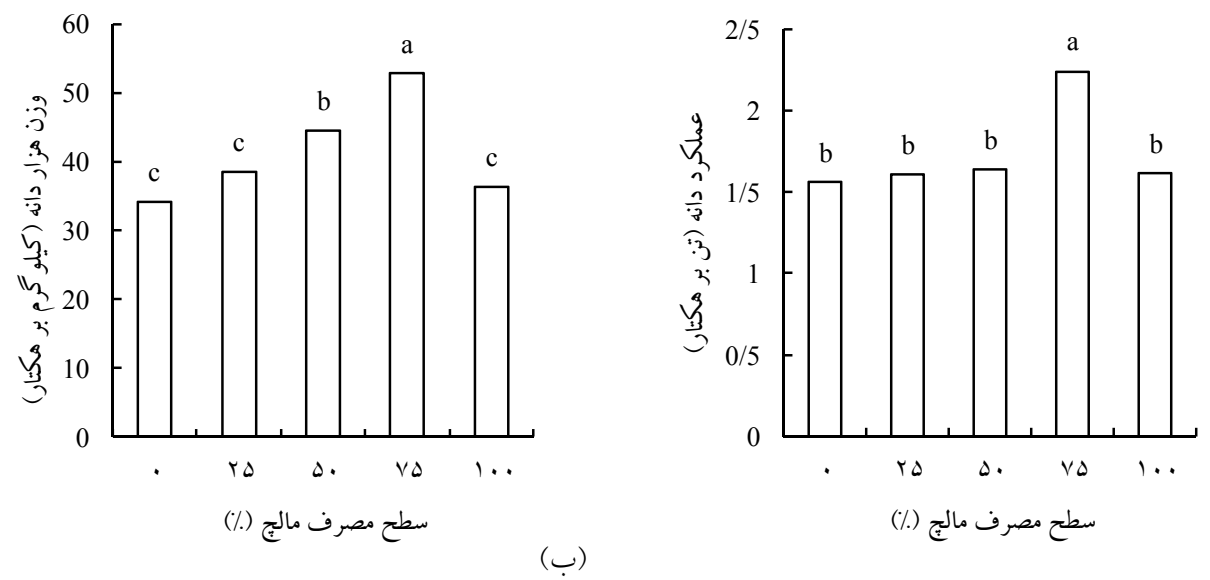

$(\varphi)$

(\%) مطح مصرف مالج (\%)
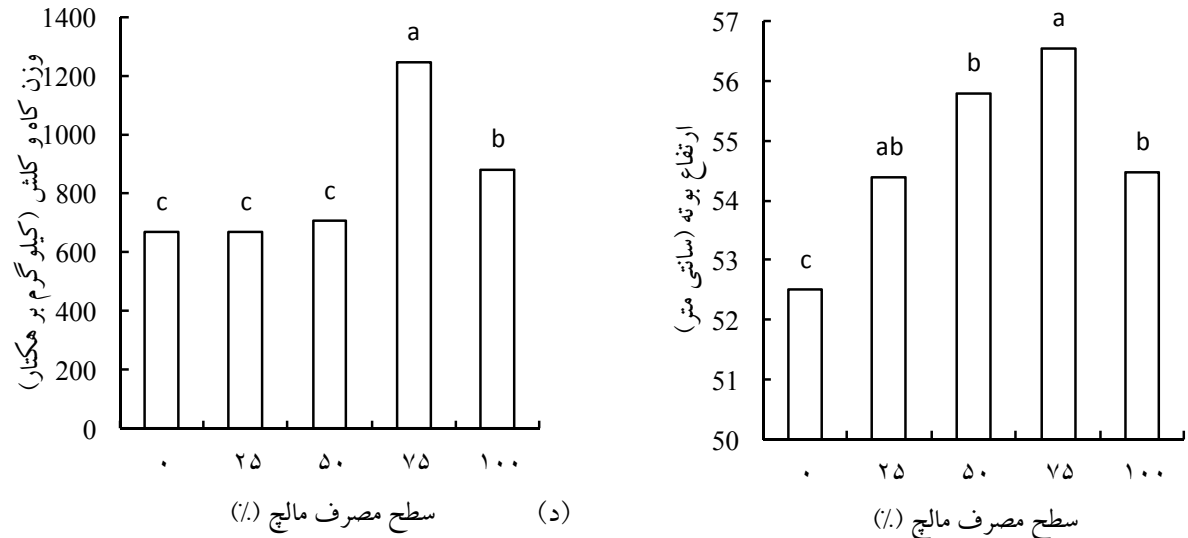

سطح مصرف مالج (\%)

(ج)

شكل r. مقايسه تاثير سطوح مختلف مالج كاهو كلش گندم بر: الف) عملكرد دانه گندم، ب) وزن هزار دانه، ج) ارتفاع بوته و د) وزن

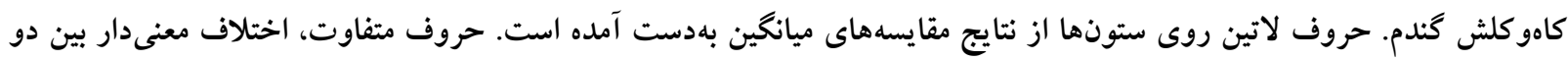
سطوح مصرف بقاياى كياهى را نشان مىدهد.

كه اختلاط بقاياى جو با خـاك، عملكـرد و جـذب نيتـروزن را

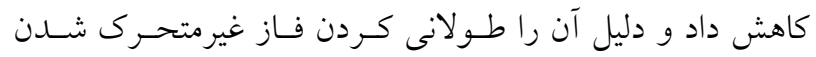

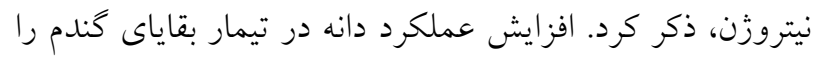

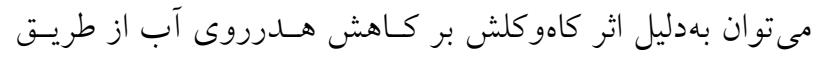

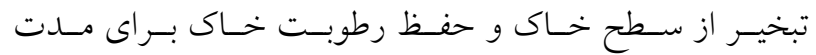
طولانى تر، بلويزه در طول ماههاى كمباران مرتبط دانست. نتسايج حاضر نشان مىدهد وجود بقاياى كياهى در خـاك در جـــب و

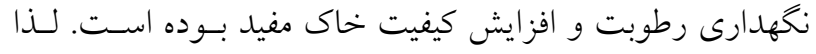

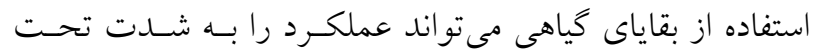

تأثير قرار دهد (T). (T).
دانه در تيمار VD درصد (T/YO تن در هكتار) كاهو كلـش كنـدم

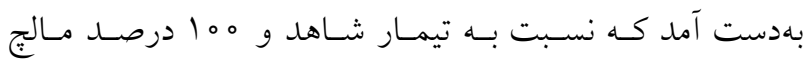

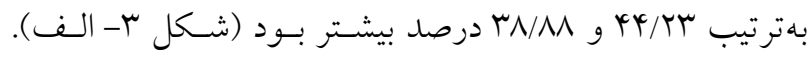

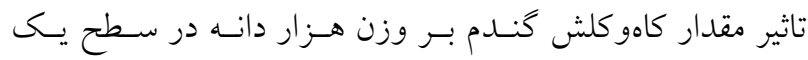
درصد (P< > P Pعنى Pار بود (جدول Y). در يزوهش حاضـر سطوح مختلف كـاهوكلـش اثـــى معنسى دار بــر وزن هـزار دانـهـ

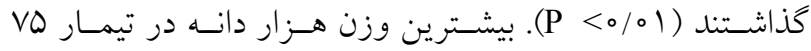
درصد مالج (MY/IV (

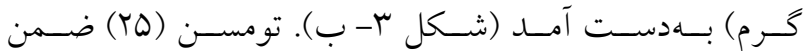
اندازهيرى آبشويى نيتروزن با استفاده از لايسيمتر كزارش كـرد 


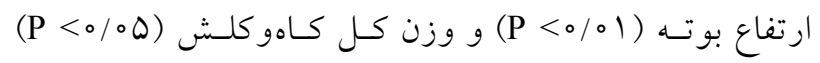

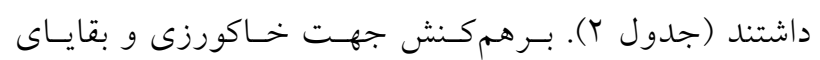

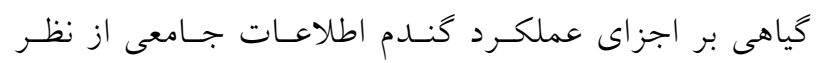

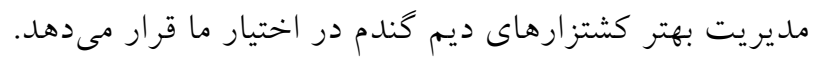

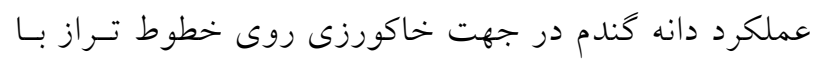

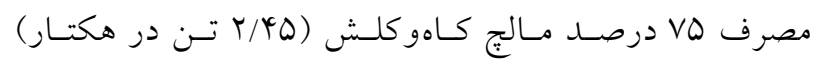

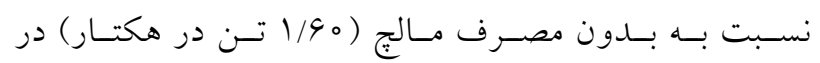

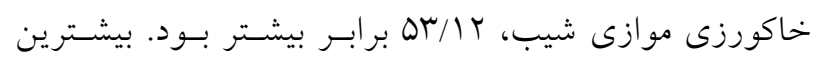

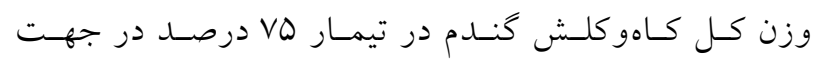

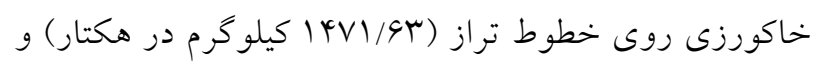

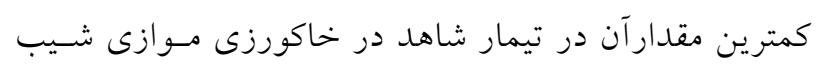

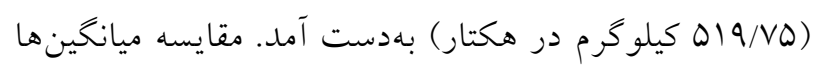

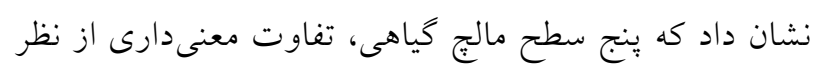

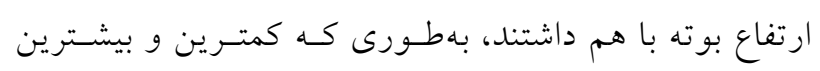

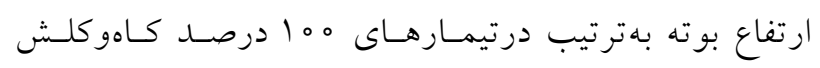

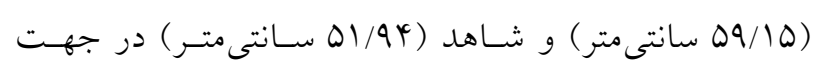

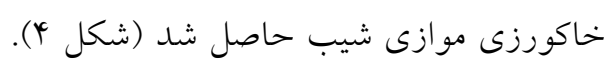

\section{نتيجه گيرى}

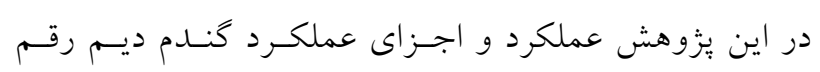

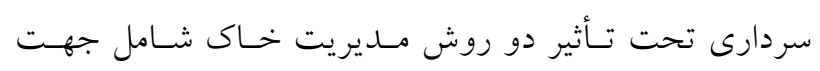

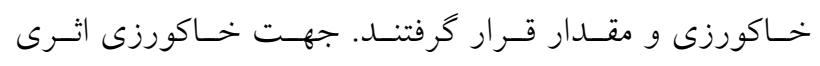

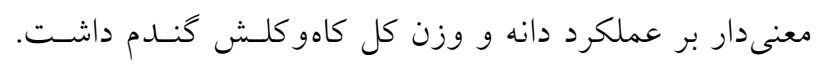

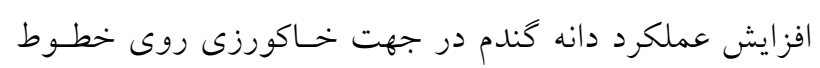

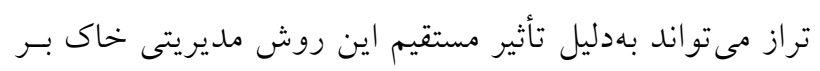

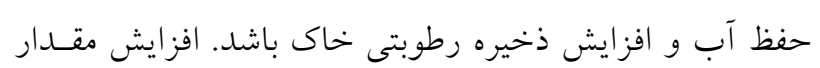

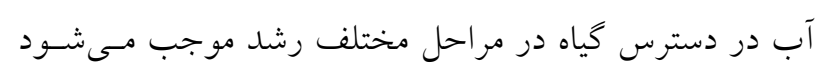

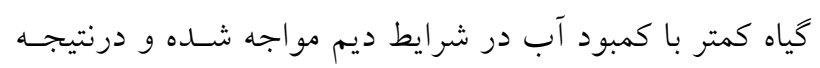

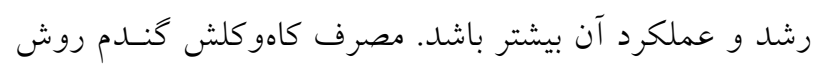

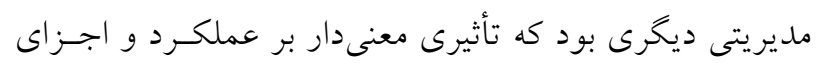

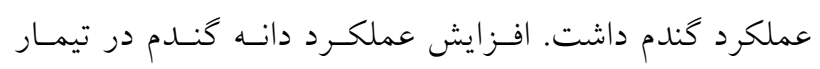

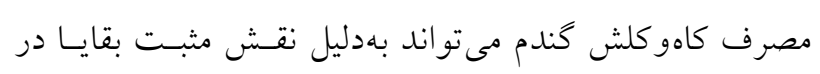

كاربرد مالج كاهو كلش كندم بر ارتفاع بوته و وزن كاهو كلـش

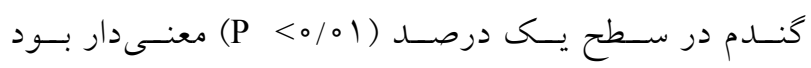
(جدول Y). بيشترين و كمترين ارتفاع بوته بهترتيب در سطح

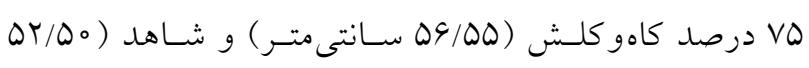

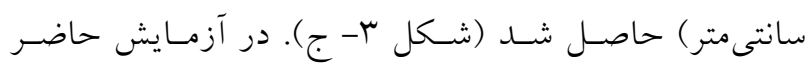

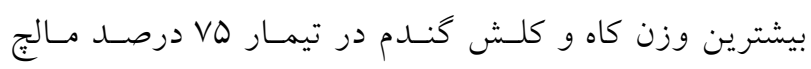

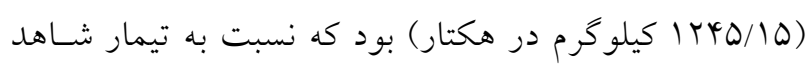

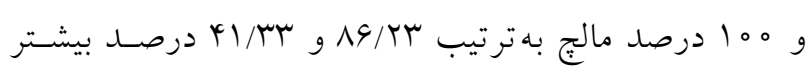

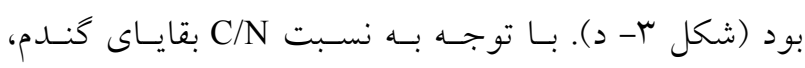

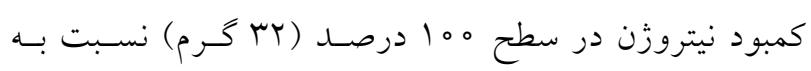

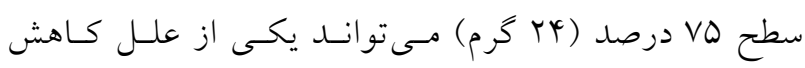

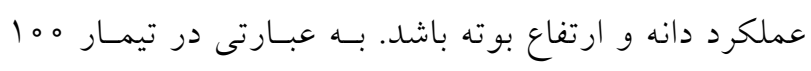

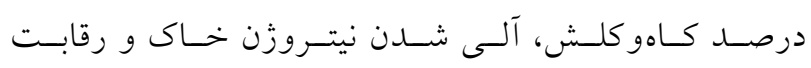

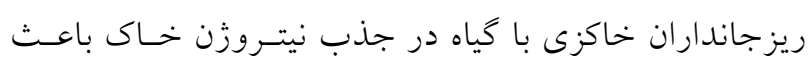

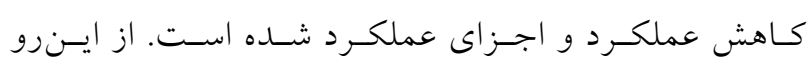

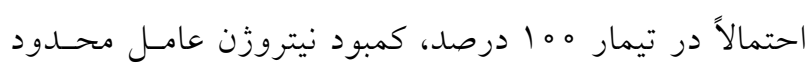

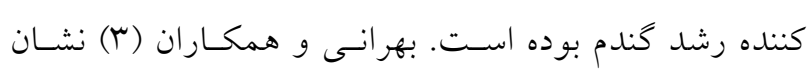

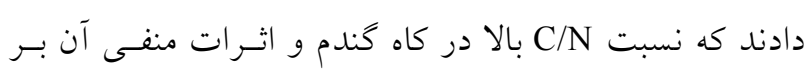
عملكرد، اثرات مثبت را خنثى مى سازد، لذا استفاده از بقاياى

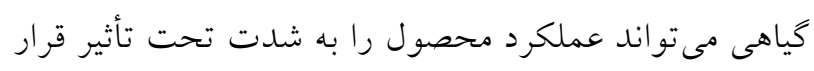

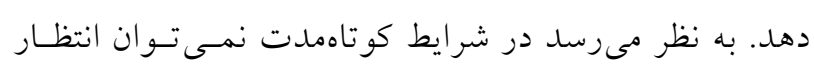

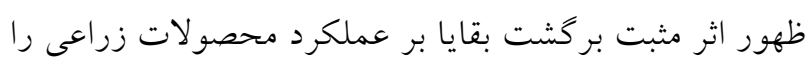

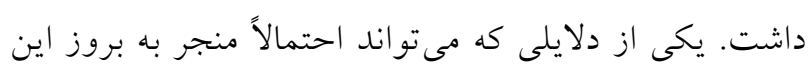

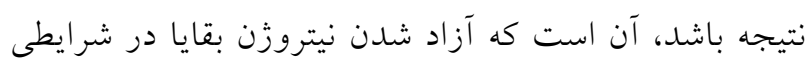

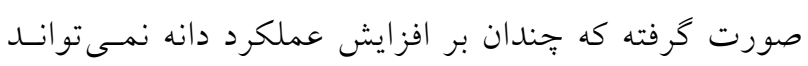

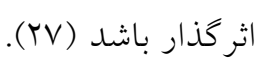

\section{برهم كنث جهـت خــاكورزى و مقـدار مصـرف مـالج روى عملكرد و اجزاى عملكرد كندم}

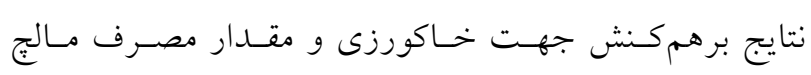
كاهو كلش كُندم نشان داد كه اين دو عامل تو أمان اثر معنى مدار

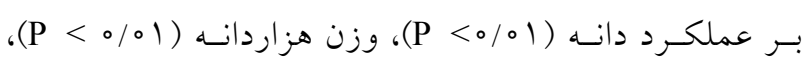



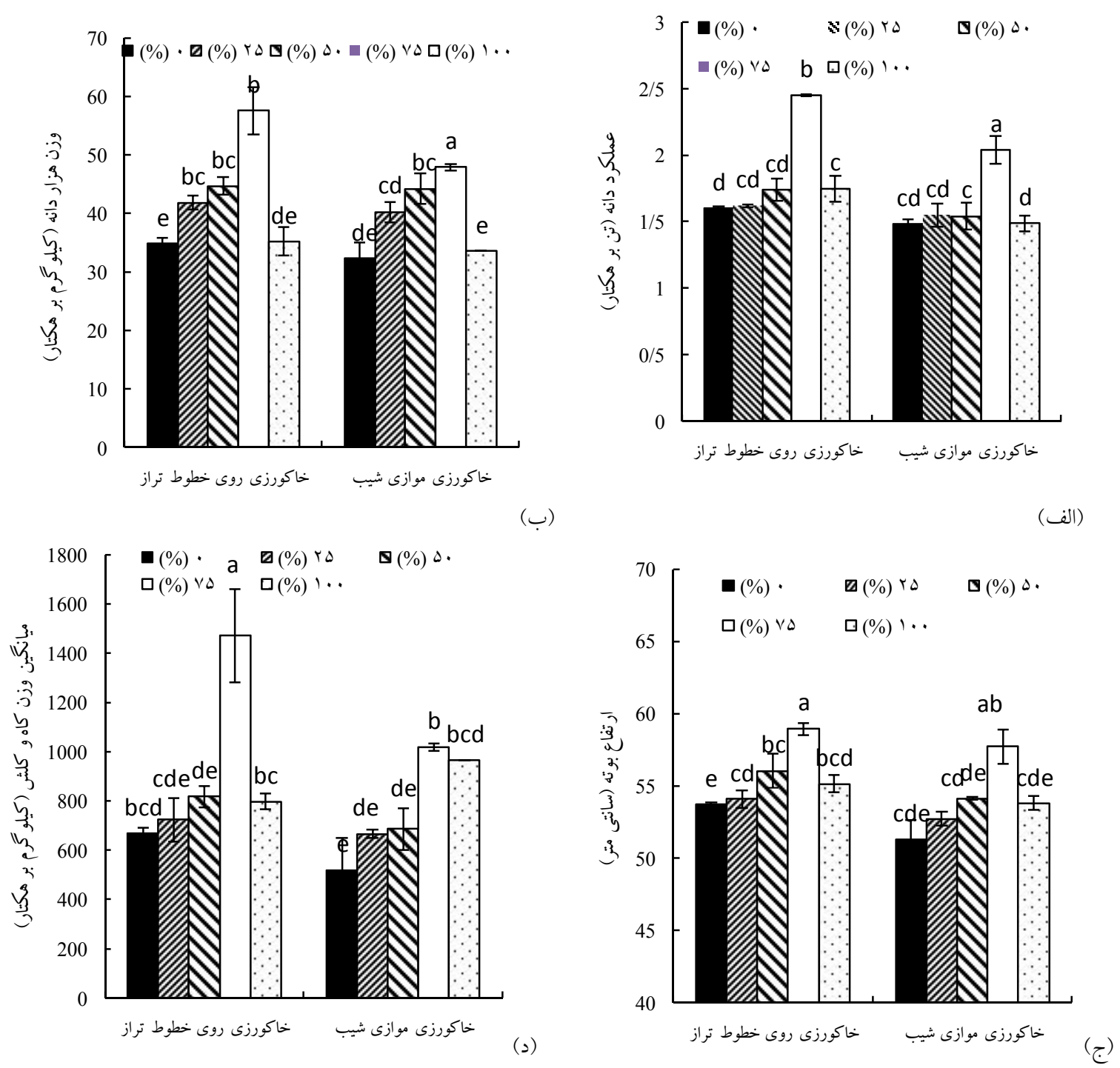

شكل †. برهم كنش سطوح مختلف مالج كاهو كلش و جهت خاكورزى بر الف) عملكرد دانه، ب) وزن هزاردانه، ج) ارتفاع بوته و د) وزن

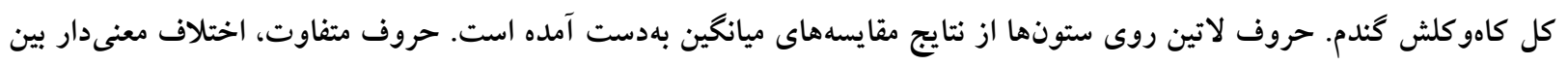

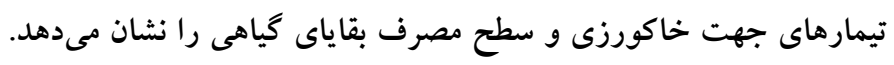

اصلاح جهت خاكورزى همراه با حفظ بقاياى گياهى و توجـه بـه

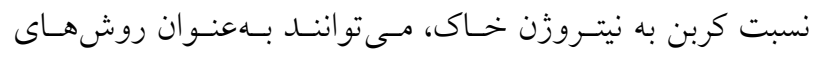

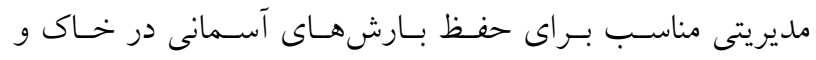

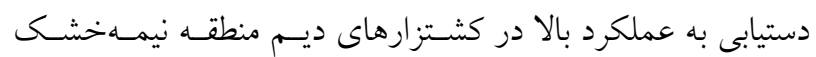
مورد توجه قرار كيرند.
افزايش ذخيره رطوبتى خاك و كاهش هدروى تبخير از سـطح

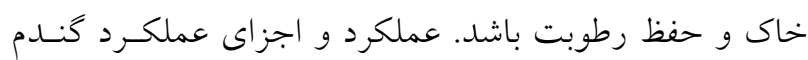

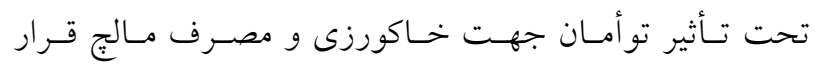

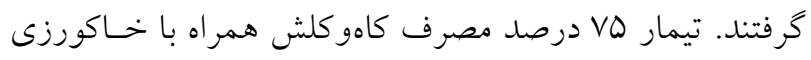

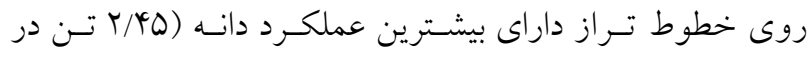

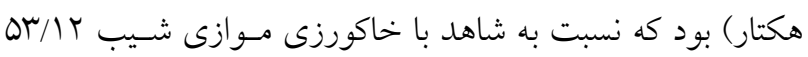

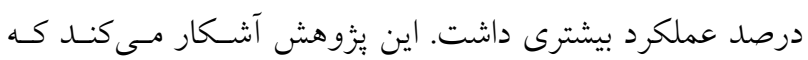


1. Adak, T., G. Kumar, N. V. K. Chakravarty, R. K. Katiyar, P. S. Deshmukh and H. C. Joshi. 2013. Biomass water use efficiency in oilseed crop (Brassica juncea L.) under semi-arid microenvironments. Biomass and Bioenergy 51: 154-162.

2. Angers, D. A. and G. R. Mehuys. 1993. Aggregatestability to water. pp. 651-657. In: Cartner, M. R. (Ed.) Soil Sampling and Methods of Analysis. Lewis Publishers, Boca Raton.

3. Bahrani, M. J., M. H. Raufat and H. Ghadiri. 2007. Influence of wheat residue management on irrigated corn grain production in a reduced tillage system. Soil and Tillage Research 94: 305- 309.

4. Brady, N. and R. Weil. 2002. The Nature and Properties of Soils, 13th Edition. Prentice Hall. Upper Saddle River, New Jersey.

5. Fischer, R. A., F. Santiveri and I. R. Vidal. 2002. Crop rotation, tillage and crop residue management for wheat and maize in the sub-humid tropical highlands. Field Crops Research 79: 107-122.

6. Gangwar, K. S., K. K. Singh, S. K. Sharmaand and O. K. Tomar. 2006. Alternative tillage and crop residue management in wheat after rice in sandy loam soils of Indo-Gangetic plains. Soil Tillage and Research 88: $242-252$.

7. Gee, G. W. and J. W. Bauder. 1986. Particle size analysis. pp. 383-411. In: Klute, (Ed.) Methods of Soil Analysis. Part $1,2^{\text {nd }}$ Ed. America Society of Agronomy. Madison.

8. Ghorbani, M. H. and H. Harutyunyan. 2011. Response growth and yield to plant density and row space under rainfed conditions in wheat. Electrical Journal Crop Production 4(2): 139-154.

9. Jones, J. B. 2001. Laboratory Guide for Conducting Soil Tests and Plant Analysis. CRC Press, Boca Raton, FL.

10. Ma, S., Z. Yu, Y. Shi, Z. Gao, L. Luo, P. Chu and Z. Guo. 2015. Soil water use, grain yield and water use efficiency of winter wheat in a long-term study of tillage practices and supplemental irrigation on the north China plain. Agricultural Water Managment 150: 9-17.

11. Mohammed, S. A. A. 2013. Contribution of weed control and tillage systems on soil moisture content, growth and forage quality of (Clitoria and Siratro) mixture underrainfed conditions at Zalingei - western Darfur state - Sudan. ARPN. Journal of Science and Technology 3: 80-95.

12. Mohanty, M., D. Bandyopadhyay, P. Painuli, A. Ghosh, K. Misra and M. Hati. 2007. Water transmission characteristics of a Vertisol and water use efficiency of rain fed soybean (Glycine max (L.) Merr.) Under subsoiling and manuring. Soil and Tillage Research 93(2): 420-428.

13. Najafinezhad, H., M. A. Javaheri, S. Z. Ravari and F. Azad Shahraki. 2009. Effect of crop rotation and wheat residue management on grain yield of maize cv. KSC704 and some soil properties. Journal of Production Seed and Plant 25-2(3): 245-258.

14. Nasresfahani, M., A. Jaberifar and A. R. Pazaki. 2013. Comparison morphologic traits wheat lines in Esfahan condition. Crop Physiology Journal 20: 103-113.

15. Nelson, D. W. and E. J. Kladivko. 1979. Surface runoff from sludge- amended soils. Journal Water Pollution Control Federation 51: 100-110.

16. Ogbonnaya, F., A. Mujeeb-Kazi, A. G. Kazi, E. L. Lagudah, S. S. Xu and D. Bonnett. 2013. Synthetic hexaploids: harnessing species of the primary gene pool for wheat improvement. Plant Breeding Reviews Journal 37: 35-122.

17. Olson, K. R., S. A. Ebelhar and J. M. Lang. 2013. Effects of 24 years of conservation tillage systems on soil organic carbon and soil productivity. Applied and Environmental Soil Science 2: 1-10.

18. Page, M. C., D. L. Sparks, M. R. Noll and G. J. Hendricks. 1987. Kinetics and mechanisms of potassium release from sandy middle Atlantic Coastal Plain Soils. Soil Science Society America Journal 51: 1460-1465.

19. Peng, Z., W. Ting, W. Haixia, W. Min, M. Xiangping, M. Siwei, Z. Rui, J. Zhikuan and H. Qingfang. 2015. Effects of straw mulch on soil water and winter wheat production in dryland farming. Scientific Report 5: 10720-10725.

20. Sang, X., D. X. Wang and X. Lin. 2016. Effects of tillage practices on water consumption characteristics and grain yield of winter wheat under different soil moisture conditions. Soil and Tillage Research 163: 185-194.

21. Sensoy, H. and Ö. Kara. 2014. Slope shape effect on runoff and soil erosion under natural rainfall conditions. iForest-Biogeosciences and Forestry 7 (2): 110.

22. Sharma, P., G. Singh and R. P. Singh. 2011. Conservation tillage, optimal water and organic nutrient supply enhance soil microbial activities during wheat (Triticum aestivum L.) cultivation. Brazilian Journal of Microbiologe 42: 531-542.

23. Stewart, B. A. 1995. Soil Management: Experimental Basis for Sustainability and Environmental Quality, CRC Lewis Publishers. Boca Raton, FL.

24. Tan, Z. and R. Lal. 2005. Carbon sequestration potential estimates with changes in land use and tillage practice in Ohio, USA. Journal of Agriculture, Ecosystem and Environment 111(1): 140-152.

25. Thomsen, I. K. and B. T. Christensen. 1998. Cropping system and residue effects on nitrate leaching and crop yield. Agriculture, Ecosystem and Environment 68 (1-2): 73-84. 
26. Tripathi, S. N., Sh. Marker, P. Pandey, K. K. J. Aiswal and D. K. Tiwari. 2011. Relationship between some morphological and physiological traits with grain yield in bread wheat (Triticum aestivum L.). Trends in Applied Sciences Research 6: 1038-1045.

27. Vanotti, M. B., S. A. Leclerc and L. G. Bundy. 1995. Short- term effects of nitrogen fertilization on soil organic nitrogen availability. Soil Science Society of America Journal 59: 1350-1359.

28. Yaseen, R., J. Shafi, W. Ahmad, M. S. Rana, M. Salim and S. A. Qaisrani. 2014. Effect of deficit irrigation and mulch on soil physical properties, growth and yield of maize. Environment and Ecology Research 2(3): $122-137$.

29. Zarrinabadi, E. and A. R. Vaezi. 2016. Runoff and soil loss as affected by land use change and plough direction in poor vegetation cover pasture. Iranina Journal of Soil and water Research 74(1): 87-98. (In Farsi). 


\title{
Dryland Wheat Grain Yield and Yield Components as Affected by Slope Direction and Residue Rates
}

\author{
A. R. Vaezi ${ }^{*}$, S. Rezaeipour and M. Babaakbari ${ }^{1}$
}

(Received: December 30-2016 ; Accepted: May 6-2018)

\begin{abstract}
Limited information is available on the effect of residues rates and slope direction on dryland wheat (Triticum aestivum L.) yield. This study was carried out to determine the effects of residues rates and tillage direction on grain yield and yield components of the Sardary wheat in a dryland region in Zanjan. Five wheat residues rates $(0$, 25, 50, 75 and 100\% surface cover) were applied and incorporated into soil in two slope directions (along the slope and on contour lines) using the randomized complete blocks design with three replications in a land with $10 \%$ slope steepness. Overall, thirty plots with $2 \mathrm{~m} \times 5 \mathrm{~m}$ dimensions were installed in the field and wheat grain yield and yield components were determined for growth period from 2015-2016. Results indicated that grain yield and yield components were significantly affected by the residues rates and slope direction and their interaction. In contour tilled plots, wheat grain yield (1.78 to per hectare), thousand grain weight $(42.26 \mathrm{~kg})$ and wheat height $(55.11 \mathrm{~cm})$ were 5.32 , $5.01,16.19$ and 1.36 percent more than the plots tilled along the slope. The highest grain yield was found in $75 \%$ of residue (2.45 ton per hectare) under contour line direction which was about $53 \%$ bigger than control treatment ( $0 \%$ straw mulch) under along the slope. This study indicated that the application of straw mulch before cultivation and incorporating into soil using contour line tillage are proper soil management methods to obtain higher wheat yield in this dryland region.
\end{abstract}

Keywords: Water conservation, Contour tillage, Wheat residues, Water supply, Semi-arid region

1. Department of Soil Science, Faculty of Agriculture, University of Zanjan, Zanjan, Iran.

*: Corresponding Author, Email: vaezi.alireza@gmail.com 